\title{
Service network design in inland waterway liner transportation with empty container repositioning
}

\author{
Fen An $\cdot$ Hao Hu $\cdot$ Chi Xie
}

Received: 8 October 2013 / Accepted: 24 February 2015 / Published online: 22 March 2015

(C) The Author(s) 2015. This article is published with open access at SpringerLink.com

\begin{abstract}
Introduction As inland shipping has been playing a more and more important role in integrated transportation system, the optimization of such a network with empty containers repositioning is of great practical significance to raise inland shipping service level so as to promote freight mode shift from land to water. This paper addresses the construction of system service network for inland water containers transportation (IWCT).

Method We incorporate the specific natures of inland waterway containers transportation and formulate the inland waterway system containers transportation into a mathematic model. It is a complex giant problem to optimize routing and fleet deployment for the whole network at the same time. Thus, a combined algorithm with genetic algorithm (GA) and Integer programming (IP) calculations are designed to solve this program. Further, a network of Yangtze River ports is studied. Results A set of shipping routes, including the calling ports, service frequency and type of the used ship of each route are
\end{abstract}

\section{F. An}

School of Naval Architecture, Ocean and Civil Engineering and also

State Key Laboratory of Ocean Engineering, Shanghai Jiao Tong

University, 800 Dongchuan Road, Shanghai, People's Republic of

China

e-mail: anne0207@yeah.net

\section{H. Hu ( $\bowtie)$}

Department of Transportation, Shipping and Logistics, School of Naval Architecture, Ocean and Civil Engineering and also State Key Laboratory of Ocean Engineering, Shanghai Jiao Tong University, 800 Dongchuan Road, Shanghai, People's Republic of China e-mail: hhu@sjtu.edu.cn

\section{Xie}

School of Naval Architecture, Ocean and Civil Engineering,

Shanghai Jiao Tong University, 800 Dongchuan Road,

Shanghai, People's Republic of China

e-mail: chi.xie@sjtu.edu.cn figured out by the IWCT network optimization model. This set of shipping routes is a combination of short routes and long routes. The direct links are commonly used for moving large quantities of containers between two ports. While for small containers flow, longer routes are used to bund cargo flows by calling as many ports as possible.

Conclusion Most present network optimization studies are focused on network design and fleet deployment about ocean and coastal container shipping. However the features of inland water shipping network are different and related studies are rare. This paper aims to fill this gap. Taking the specific features of IWCT into consideration, the proposed model is suitable for the service network design in IWCT network. And the experimental results verify the validity of the combined algorithm. Point-to-point direct route is the most economic mode for large cargo flows between ports. When the containers flow is small, routes calling at multiple ports can achieve economies of scale through bundling.

Keywords Inland waterway liner shipping - Service network · Containers bundling · Empty containers repositioning ·

A combined algorithm with GA and IP

\section{Introduction}

Road and rail have been the dominant freight transportation modes for decades and such a dominant pattern will not be significantly altered in the foreseeable future. However, the continuously increasing freight demands over the ground transportation network in many regions worldwide reach a point where alternative means of augmenting its capacity may not provide a cost-effective and environmentally friendly solution. Building more roadways and railways and expanding their branches and capacities require huge capital 
investments and impose an increasing financial pressure on the governments and taxpayers. Induced freight demands from the ground network expansion further deteriorate traffic congestion, energy consumption and air pollution conditions. Inland waterway container transport (IWCT), as characterized by its relatively lower cost, higher capacity, more reliable operations, and apparently reduced environmental impacts compared to ground transportation sectors, has been playing an increasingly important role in the integrated ground-water transportation system.

Specifically, as is known, the energy consumption rate of inland waterway transport is approximately 17 and $50 \%$ of that of road transport and rail transport, respectively. It offers a congestion-free network connecting cities along river corridors and contributes to the decongestion of the overloaded road networks. A modal shift from road to inland water transport could be an appealing measure to reduce vehicle emissions and relieve corridors congestions from trucks. In the European Union, which is also confronted with traffic congestion and pollution, all levels of government are convinced that an accelerated development of a modal shift from road towards inland navigation is one of the key requirements for reducing congestion and environmental externalities. The Marco Polo Program is typical strategy through which Europe aims to sustainable transportation by shipping more goods by water.

The potential of IWCT will be further explored against this background. According to CHINA PORTS YEARBOOK(2013), From 2004, China's inland waterway container transportation volume has grown from 2 million TEU to nearly 10 million TEU and will continue to surge. The rising transport volumes create opportunities for improvements in container transportation organization and efficiency. However, IWCT is still in the development period especially in China where IWCT has been neglected for a long time. The lack of effective guidance for planning restricts the entire development of IWCT. In recent years, the importance of IWCT has been increasingly aware and the number of container transportation routes has increased, but many problems occur because of the lack of system planning. The opening of routes for IWCT relies heavily on rules of thumb and qualitative analysis that does not rely on sufficient scientific data thereby making it difficult to obtain the optimality of route planning. Many shipping companies set routes almost voluntarily so that routes are overlapping and partial capacity is wasted while the transportation demand of other ports cannot be satisfied. This has reduced the benefits of IWCT and hindered the full utilization of IWCT potentials, which is not in favour of IWCT services improvement and modal shift. An increased level of coordination is necessary to organize the intermodal transport flow. The cost and quality of IWCT services are closely related to the network operations within which they run.
In conclusion, to increase competitiveness of IWCT versus road transport so as to promote modal shift from road to water and deal with the increasing inland waterway traffic volume, An efficient well-organized inland shipping system is essential. IWCT service network design must be carried out scientifically so as to increase the service level and reduce cost of IWCT, service networks can play this role. And fixed shipping schedules can increase the reliability of IWCT further.

Network operation can consolidate different container flows in a network so as to create denser freight flows and achieve economies of scale. According to Wieberneit [1], the service network design problem needs to answer: what are the best set of routes as well as the characteristics of each service? Which kind of ship with what capacity should be used to run each route? How should the containers be routed through this network of services to meet customer service requirements? To ensure the transportation quality of IWCT and attract cargo flows from land transportation, one important aspect that shouldn't be neglected is that the designed network must satisfy the laden containers transportation demands during the predictive period. Besides, because of imbalances of trade flows, some terminals or ports will create a surplus of empty containers, while others will face a deficit. To correct these differences, empty containers have to be repositioned, such that they can answer the demand of the next period and ensure the system sustainability. On the other hand, the choice of routes will be also influenced by the empty container flow, resulting in an optimum network, both for loaded and empty cargo. Therefore general empty balancing strategies have to be part of service network design.

\section{Literature review}

The problems of network design and network coordination have received most attention in literature of recent years. In transportation systems where service cannot be tailored for each customer, service network design plays an important role and is an important field of both shipping planning and intermodal transportation.

Sambracos et al. [2] study the coastal freight shipping problem to investigate the introduction of small containers for freight transport in a network of islands. The optimization of weekly routes in liner shipping is modeled as a vehicle routing problem with time constraints by Fagerholt [3] and Karlaftis et al. [4]. Christiansen et al. [5] described models for designing shipping networks for a traditional liner operation as well as for a hub-and-spoke liner network. Hsua and Hsieha [6] formulated a two-objective model to determine the optimal liner routing, ship size, and sailing frequency for container carriers. Their research was targeted at hub-and-spoke network which has become popular for container carriers to provide their services as the global trade keeps expanding, and cargo traffic 
keeps growing. A mixed integer linear programming formulation was proposed for the simultaneous design of network and fleet deployment of a deep-sea liner service by Gelareh and Pisinger [7]. Meng and Wang [8] propose a network design formulation for intermodal hub-and-spoke networks which allows container transshipment operations at any port. However, although there have been a large number of studies about network design and fleet deployment for container transportation in shipping, most of these studies found are focused on the ocean and coastal container shipping whose features are different from those of inland water shipping.

As presented by Caris et al. [9], the research about the intermodal service network design and the determination of an optimal consolidation strategy is identified as a research field requiring more attention. Sharypova [10] further pointed out the significance of this research for inland water transportation. However, most researches about the intermodal service network design are for railway and truck transportation (Newman and Yano [11]; Racunica and Wynter [12]; Yoon and Current [13]; Andersen et al. [14]). A joint state-of-the-art review of service network design modeling efforts and mathematical programming developments for network design were presented by Crainic [15]. Those researches provided an overview on how to model real-life problems and what should be taken into consideration to construct a network system.

Although the network design in inland waterway containers transport demonstrates similarities with the container shipping network design problem in ocean networks and railway networks respectively, inland waterway container transportation has its own specific characters which will be analyzed later, therefore, the IWCT deserves particular attentions. In addition, despite of the comparable abundance of research of network design in ocean shipping and railway transportation, most of the above-studies didn't cover all aspects of network design as presented by Wieberneit [1]. Few papers considered the simultaneous optimization of loaded and empty container flows. Moreover, they didn't consider OD flows between the ports or inland terminals. However, all those aspect need to be taken into account to construct efficient IWCT network.

The significance of network coordination strategies for inland waterway container transportation has been fully understood and demonstrated. Van der Horst and De Langen [16] emphasized the need for coordination in hinterland container transport chains. Specifically for inland container transportation, Caris [17] developed a methodology to calculate and compare system cost of two cooperation scenarios with the situation in which different terminals operate independently. The result showed that both the two cooperation appeared to be more beneficial thus demonstrated potential benefits of cooperation and network design as a whole. The importance of bundling networks of container barge transport in the port area of Antwerp was further demonstrated by Caris et al. [18] using a discrete event simulation model. A similar conclusion through numerical results was obtained by Sharypova [10] who addressed the problem of network coordination strategies in barge container hinterland transportation.

However, despite the importance of network coordination strategies, the service network design for inland waterway containers transportation is still very rare both practically and theoretically. Especially in China, remaining at initial development stage, the inland waterway container transportation has not got enough scientific organization and guidance. Veenstra et al. [19] introduced a five-layer model to identify the existing or potential restrictions to container shipping. The analysis showed that there is no immediate capacity shortage in either ports or the fleet, but current service networks are inefficient. If the service networks can be improved, up to twice as much cargo with the same amount of ships can be transported.

Theoretically, the service network design of inland waterway container transportation has also received little attention. To the authors' knowledge, only Maras [20] and Yang [21] studied specifically on route optimization and network design of IWCT. Adapting a model introduced by Shint ani et al. [22] for service network design in maritime shipping, Maras [20] investigated the design of an optimal barge shipping route. Although he considered OD flows between different ports and empty container repositioning, not all transportation demands were satisfied. Using LINGO, His paper only determined an optimal route for five considered tows each other than a generic network. Yang [21] constructed a network for Yangtze River, but he didn't take empty containers reposition into consideration.

In this paper, we incorporate the specific natures of IWCT and formulate the system into a mathematic model to optimize IWCT network which can satisfy transportation demands with a minimal system cost. The model is solved by the combination use of Generation Algorithm and Integer Programming to determine the needed set of liner routes, the calling ports, calling sequence and service frequency of each route, type of the used ships.

This paper is organized as follows: Section 3 analyses the characteristics of inland waterway routes and presents the problem statement. We describe the mathematic model of IWCT network design in section 4 and designs the algorithm in section 5. Section 6 illustrates a case study. Finally, section 7 draws the conclusions and identifies future research opportunities.

\section{Problem statement}

3.1 Analysis of inland waterway transportation routes' characteristics

Before formulating the mathematic model for IWCT networks, we describe the characteristics of inland waterway 
transportation routes first. The base of inland water shipping is rivers that have tree structures with the trunk waterway and different 'branches'. We only consider the trunk waterway in this paper. This is valid because most 'branches' are usually not navigable. Different from ocean shipping, inland water shipping has unique features about its routes, ships and networks which can be concluded as follows:

\subsubsection{Line structure of ports' location}

All ports are situated across a single river axis (Fig. 1). Owing to this geographical restriction, a ship can only navigate along the river from one port to another in sequence. In marine shipping, a route is determined by both the calling ports and the calling sequence. But for inland shipping route, it is only the calling ports that need to be decided. The sequence is predetermined and should also be observed in the route's construction process.

A ship in an inland shipping route starts from its head-end port, travels to its tail-end port of this route and then returns to the head-end port. This route is closed and can be divided into forward sub-route and backward sub-route by two directions. Figure 1 shows an example of this route, where port 2 is the head-end port and port 6 is the tail-end port. Along the route, one or some ports in-between may be visited. The intermediate ports visited in forward sub-route may differ from those visited in backward sub-route as showed in Fig. 1. Both the head-end port and the tail-end port of the route are not fixed and are determined by the system network model of optimization.

\subsubsection{Physical restrictions}

During to the physical conditions, some sections, mostly in upstream of rivers, are not navigable because of draft restriction. Even those navigable segments have different drafts. The vessel capacity that can be deployed is thus restricted and not homogeneous due to varying draft limitations and other physical conditions in various parts of the river system. Those other physical conditions contain the existence of locks and bridges which are unique to inland waterway. They constitute some barriers to inland shipping. The locks extend voyage time while the ship type and loaded containers' number can be restricted by the clear height of the bridge. Therefore their influence must be taken into account in the network optimization. In our study, we temporarily just consider the locks' impact.

\subsection{Problem statement}

In the inland river system, each port is both a discharging port that receive containers form all other ports and a loading port that export containers to other ports. In other words, there can be containers transportation flows between any two ports, or OD flows which are marked as $\mathrm{F}_{\mathrm{ij}}$ in the model later. All these OD flows must be fulfilled to maintain a certain customer service-level and promote the mode shift. Because some OD flows are small and the transportation volumes between forward sub-route and the backward sub-route are imbalance. Simple point to point transportation cannot guarantee efficient operations. The basis of a service network design consists of the bundling of freight flows that can help direct flows along paths so as to realize economies of scale.

In line with Wieberneit [1], the aim of IWCT network design problem aims to construct a set of ship routes to bundle and fulfill all OD freight flows $\left(\mathrm{F}_{\mathrm{ij}}\right)$ in this system, meanwhile, the reposition of empty containers are also needed to be finished to realize the system's balance. On the basis of satisfying the transportation demand, this set of routes should be operated at minimum system cost. For each route, which ports to be visited, as well as the type of ships deployed on this ship route and the service frequency are also needed to be determined.

For the convenience of research and to facilitate the abstraction of practical problem, the following assumptions are made: (1) Each OD pair containers transportation volume can be obtained beforehand through prediction. (2) Owing to different speed of different ship types, only one type of ships are used in the same route to maintain a regular shipping schedule.

\section{Upstream $\quad$ Forward route $\quad$ Downstream}

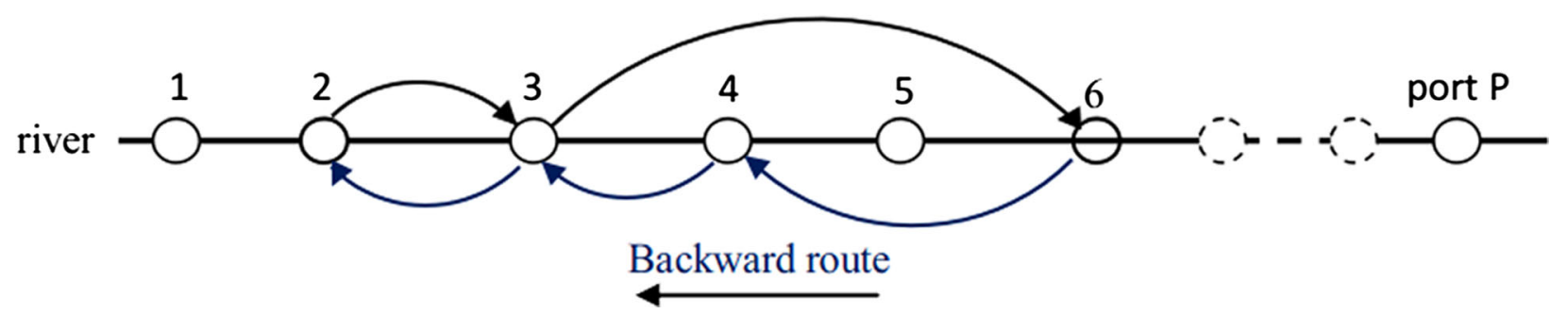

Fig. 1 location of ports in the river 


\section{Mathematical model}

Based on the statement of the problem, some parameters about the aim of the network design are given first:

- $\quad x_{i j}^{r}$ is a binary variable, $x_{i j}^{r}=1$ is ports $i$ and $j$ are directly connected in a route, otherwise, it equals 0 . After all $x$ ${ }_{i j}^{r} \quad \forall i, j \in P$ are determined, then the structure of route $r$ is determined. $P=\{1,2, \ldots \ldots, P\}$ is the set of ports in the targeted inland waterway system.

- $F_{i j}^{r}$ represents the number of containers split to route $r$. In reality, the same OD flow containers can be transported by different routes so as to realize combinatorial optimization.

- $E_{i j}^{r}$ is the empty containers repositioned from port $i$ to $j$ by route $r$. Using the spare space of ships, the reposition of empty containers is carried out along with the transportation of loaded containers.

- $s_{k}^{r}, k \in K$ is a binary variable that indicate which type of ship is deployed in route $r$. If ship type $k$ is deploy in route $r$, then $s_{k}^{r}=1$, otherwise equals $0 . K=\{1,2,3 \ldots K\}$.

- $f_{r}$ is the service frequency of route $r$.

\subsection{Objective function}

As stated above, by the designed network's bundling effect, our aim is to realize the minimization of system cost during the planning horizon $H$. The network is composed of a set of routes and suppose the number of routes is $R$. During the planning horizon, the round-trip cost of each route is made up of the voyage cost $S_{r}$, fixed cost $C_{r}$ and system empty containers reposition $\operatorname{cost} E$. Then the formulation of objective function can be stated as:

$M I N$

$$
Z=\sum_{r \in R}\left(S_{r} \cdot f_{r}+C_{r}\right)+E
$$

(1) The voyage cost of route $r$ consists of fuel cost fuel $_{r}$, port entry cost port $_{r}$ loaded container handling cost $c l d_{r}$

$S_{r}=$ fuel $_{r}+$ port $_{r}+$ cld $_{r}$

The fuel cost of route $r$ is closely related with the ship type deployed on it. $\alpha_{k}$ is the daily fuel cost of ship type $k$. For route $r$, only the deployed ship type is used to calculate its fuel cost. $T_{r}$ is the round-trip time of route $r$ and it will be calculated later.

$$
\text { fuel }_{r}=\sum_{k=1}^{K} s_{k}^{r}\left(a_{k} \cdot T_{r}\right)
$$

With the entry cost per call at port $i p c_{i}$, port entry cost of route $r$ can be calculated as:

$$
\begin{aligned}
& \text { port }_{\mathrm{r}}=\sum_{\mathrm{i} \in \mathrm{P}} \sum_{\mathrm{j} \in \mathrm{P}} \mathrm{x}_{\mathrm{ij}}^{\mathrm{r}} \cdot \mathrm{pc}_{\mathrm{i}} \\
& \text { port }_{\mathrm{r}}=\sum_{\mathrm{i} \in \mathrm{P}} \sum_{\mathrm{j} \in \mathrm{P}} \mathrm{x}_{\mathrm{ij}}^{\mathrm{r}} \cdot \mathrm{pc} \mathrm{c}_{\mathrm{i}}
\end{aligned}
$$

$l c f_{i}, l d f_{i}$ are the loading and discharging cost per loaded container in port $i$ respectively. As a result, loaded container handling cost $c l d_{r}$ in fact can be omitted although container handling cost is an essential part of the overall cost. Because our aim is to satisfy the transportation need of OD flows whose number is predetermined, the overall operations of handling do not change with the design scheme of system network. Therefore, cld $_{r}$ is invariable for the whole system and can be omitted from the overall cost minimization process.

(2) The fixed cost of route $r C_{r}$

Because of the water depth difference between dry season and wet season, the optimal IWCT network should be adjusted in accordance. The fleet deployment is also different, therefore the fixed cost during the planning horizon cannot be specifically counted with the depreciation cost of buying ships. We thus use time charter cost as a replace.

$$
C_{r}=\sum_{k=1}^{K} s_{k}^{r}\left(\beta_{k} \cdot T_{r} \cdot f_{r}\right)
$$

Where $\beta_{k}$ is the daily charter cost of ship type $k$

(3) System empty containers reposition cost $E$.

The demand for empty containers at a port, at a specific point of time, is the difference between the total traffic originating from the port and the total loaded container traffic arriving at the port for that specified time period.

containers arriving at port $i$

$$
A_{i}=\sum_{j \in P} F_{j i} \quad \forall i \in P
$$

containers originating from port $i$

$D_{i}=\sum_{j \in P} F_{j i} \quad \forall i \in P$

then:the empty containers surplus in port $i$

$\operatorname{sur}_{i}=\max \left\{A_{i}-D_{i}, 0\right\} \quad \forall i \in P$ 
the empty containers shortage in port $i$

$\operatorname{sho}_{i}=\max \left\{D_{i}-A_{i}, 0\right\} \quad \forall i \in P$

To answer the container using demand of the next period and maximum the profit of an optimal route, leasing and storage strategies are usually adopted along with reposition (20). However, for the network system, continuously leasing containers at a certain port and storing containers at another port cannot ensure the system sustainability. Therefore, no leasing and storage option is considered in the IWCT network design system. Empty containers are repositioned from surplus ports to those insufficient ones by using excess capacity of container ships that transportation cost of empty containers can be omitted. The system's overall operations of handling empty container also do not change with the design scheme of system network. Therefore, empty containers handling cost also does not impact the overall cost minimization process. In conclusion, in contrast with Maras [20], system empty containers reposition cost $E$ can be deleted from the objective function.

To sum up, the objective function is

$z=\sum_{r}\left[T_{r} \sum_{k=1}^{K} s_{k}^{r}\left(\alpha_{k}+\beta_{k}\right)+\sum_{i \in P} \sum_{j \in P} x_{i j}^{r} p c_{i}\right] f_{r}$

The round-trip time $T_{r}$ is the sum of the ship navigation time, port entry time and containers handling time including loaded containers and empty containers.

$T_{r}=T N_{r}+T E O_{r}+T L D F_{r}+T L D E_{r}$

- The ship navigation time is calculated for every segment between every two ports on the route. If ports $i$ and $j$ is closely related on the route $r$, then the path between ports $i$ and $j$ is called a segment of route $r$, and navigation time in this segment is calculated according to distance between ports $i$ and $j$ in the river $l_{i j}$ and the deployed ship type whose average speed is $v_{k}$. Besides, as analyzed before, inland shipping efficiency is largely affected by the existence of locks. The time $l k_{i j}^{r}$ needed to pass all the locks between ports $i$ and $j$ should be calculated in.

$$
T N_{r}=\sum_{i \in P} \sum_{j \in P}\left(\sum_{k=1}^{K} s_{k}^{r}\left(\frac{l_{i j}}{v_{k}^{r}}+l k_{i j}\right) x_{i j}^{r}\right)
$$

- $\quad$ Port entry time of route $r$

$$
T E O_{r}=\sum_{i \in P} \sum_{j \in P}\left(x_{i j}^{r} \cdot e t_{i}\right)
$$

Where $e t_{i}$ is the time needed to entry port $i$.

- Loaded containers handling time of route $r$

$$
T L D F_{r}=\sum_{i \in P} \sum_{j \in P} F_{i j}^{r}\left(l t f_{i}+d t f_{i}\right)
$$

Where $l t f_{i}$ is the loading time per loaded container $d t f_{j}$ is the discharging time per loaded container

- empty containers handling time of route $r$

$$
T L D E_{r}=\sum_{i \in P} \sum_{j \in P} E_{i j}^{r}\left(l t e_{i}+d t e_{j}\right)
$$

Where $l t e_{i}$ is the loading time per empty containerdte $e_{j}$ is the discharging time per empty container

\subsection{Constraints}

(1) Based on historic data and recent development, any OD container flows can be predicted. The forecasted requests need to be covered to maintain a certain customer service-level.

$\sum_{i \in P} \sum_{j \in P} F_{i j}^{r}=F_{i j}$

(2) Empty containers repositioned into port $i$ should meet the shortage in this port.

$\sum_{j \in P} \sum_{r} E_{j i}^{r}=s h o_{i}$

(3) Empty containers repositioned out of port $i$ should equal the surplus in this port.

$\sum_{j \in P} \sum_{r} E_{j i}^{r}=s u r_{i}$

(4) Ship capacity restrictions. For any route $r \in R$, the overall loaded and empty containers should not exceed the capability $u_{k}$ of the deployed ship type.

Forward sub-route:

$$
\begin{aligned}
& \sum_{m=1}^{i} \sum_{n=j}^{p}\left(F_{m n}^{r}+E_{m n}^{r}\right) \leq f_{r}\left(\sum_{k=1}^{K} s_{k}^{r} u_{k}\right)+M\left(1-x_{i j}^{r}\right) \\
& i=1,2, \ldots, P-1 ; j=i+1, \ldots, P ;
\end{aligned}
$$


Backward sub-route:

$$
\begin{aligned}
& \sum_{m=i}^{p} \sum_{n=1}^{j}\left(F_{m n}^{r}+E_{m n}^{r}\right) \leq f_{r}\left(\sum_{k=1}^{K} s_{k}^{r} u_{k}\right)+M\left(1-x_{i j}^{r}\right) \\
& \quad i=2, \ldots, P ; j=1, \ldots, i^{-1} ;
\end{aligned}
$$

Where: $M$ is a large number.

(5) Round trip restrictions,suppose the head-end port of route $r \in R$ is $q_{1}$, while the tail-end port of route $r \in R$ is $q_{2}$. In the liner shipping network design problem a vessel must leave each port it enters.

$$
\begin{aligned}
& \sum_{i=q_{1}}^{q-1} x_{i q}^{r}-\sum_{j=q+1}^{q_{2}} x_{q j}^{r}=0 \quad q=q_{1}+1, \ldots, q_{2}-1 \\
& \sum_{i=q+1}^{q_{2}} x_{i q}^{r}-\sum_{j=q_{1}}^{q-1} x_{q j}^{r}=0 \quad q=q_{1}+1, \ldots, q_{2}-1 \\
& \sum_{i=0}^{q_{1}-1} \sum_{j=i+1}^{q_{1}} x_{i j}^{r}=\sum_{i=q_{1}} \sum_{j=q_{1}-1}^{q_{1}} x_{i j}^{r}=0 \\
& \sum_{i=q_{2}}^{n} \sum_{j=q_{2}+1}^{n+1} x_{i j}^{r}=\sum_{i=n+1}^{q_{2}+1} \sum_{j=i-1}^{q_{2}} x_{i j}^{r}=0
\end{aligned}
$$

(6) no loaded or empty containers are transported between two ports when at least one of these two ports is not called.

Forward sub-route

$$
\begin{aligned}
& F_{i j}^{r}+E_{i j}^{r} \leq M\left(\sum_{q=i+1}^{j} x_{i q}^{r}\right)\left(\sum_{q=1}^{j-1} x_{q j}^{r}\right) \\
& \mathrm{i}=1,2, \ldots, \mathrm{p}-1 ; \mathrm{j}+1, \ldots, \mathrm{p}
\end{aligned}
$$

Backward sub-route

$$
\begin{aligned}
& F_{i j}^{r}+E_{i j}^{r} \leq M\left(\sum_{q=i-1}^{j} x_{i q}^{r}\right)\left(\sum_{q=j+1}^{i} x_{q j}^{r}\right) \\
& \mathrm{i}=2, \ldots, \mathrm{p}-1 ; \mathrm{j}=1, \ldots, \mathrm{i}-1
\end{aligned}
$$

Where: $M$ is a large number.

(7) Only one type of ships are used in the same shipping route.

$$
\sum_{k=1}^{K} s_{k}^{r}=1 \quad r \in R
$$

(8) Draft restrictions. In this paper, we convert the draft constraint into the largest container capacity $G_{i j}$ that is admitted between port $i$ and port $j$.

$$
\sum_{k=1}^{K}\left(s_{k}^{r} u_{k}\right) x_{i j}^{r} \leq G_{i j} \quad \forall i, j \in P ; \quad r \in R
$$

\section{Solution algorithm}

It is a complex giant problem to optimize routing and fleet deployment for the whole network at the same time. Large network design problems that arise in practice are unlikely to be solved directly as linear programs, so it is impossible to directly take for optimization. Thus, a heuristic process is proposed as Fig. 3. A genetic algorithm (GA) and Integer programming (IP) calculations are combined to design the needed network. Before the solution algorithm is given in detail, we first introduce another two binary variables to assist the solving process.

- $\quad O_{i j}^{r}$, if route $r$ is used to transport containers from port $i$ to port $j, O_{i j}^{r}=1$ (else 0$)$.

- $y_{i}^{r}$, if route $r$ call port $i, y_{i}^{r}=1($ else 0$)$.

IWCT network design deals with how to satisfy transportation demands with a minimal system cost. Given the transportation volume $\left[F_{i j}\right]$ and the empty containers imbalance $\left[\right.$ sur $\left._{i}\right]$ and $\left[\right.$ sho $\left._{i}\right]$ that need to be covered by the system network, the problem IWCT network design equals to how to distribute both loaded and empty containers into a set of routes sufficiently for transportation so as to minimize the system cost. The relation between the distribution and decision variables can be described as Fig. 2

$\left[F_{i j}\right]\left[\right.$ sur $\left._{i}\right]$ and $\left[s h o_{i}\right]$ are divided into $R$ routes (constraints (1) (2) (3)). Therefore, according to the distribution result, the call ports of each route will be determined, because if route $r$ is assigned to transport containers from port $i$ to port $j$, that is $O_{i j}^{r}=1$, then both those two OD ports needed to be called by route $r$ (constraints (6)), and then $y_{i}^{r}=y_{i}^{r}=1$. Due to the line structure of ports' location and round trip restrictions (5), each route's configuration $x_{i j}^{r}$ can be decided by the determination of calling ports. With configuration $x_{i j}^{r}$ and constraints (7) and (8), the useable ship type of route $r$ is also decided. Constraints (4) describe the restrictive relation among volume distribution, ship type $s_{k}^{r}$ and service frequency $f_{r}$.

Because constraints (5) and (6) are hard to deal in the modal, based on the above analysis, a GA is designed to search for the best combination of routes, while Integer programming is used to determine the ship capacity for each route and optimize the containers distribution. 


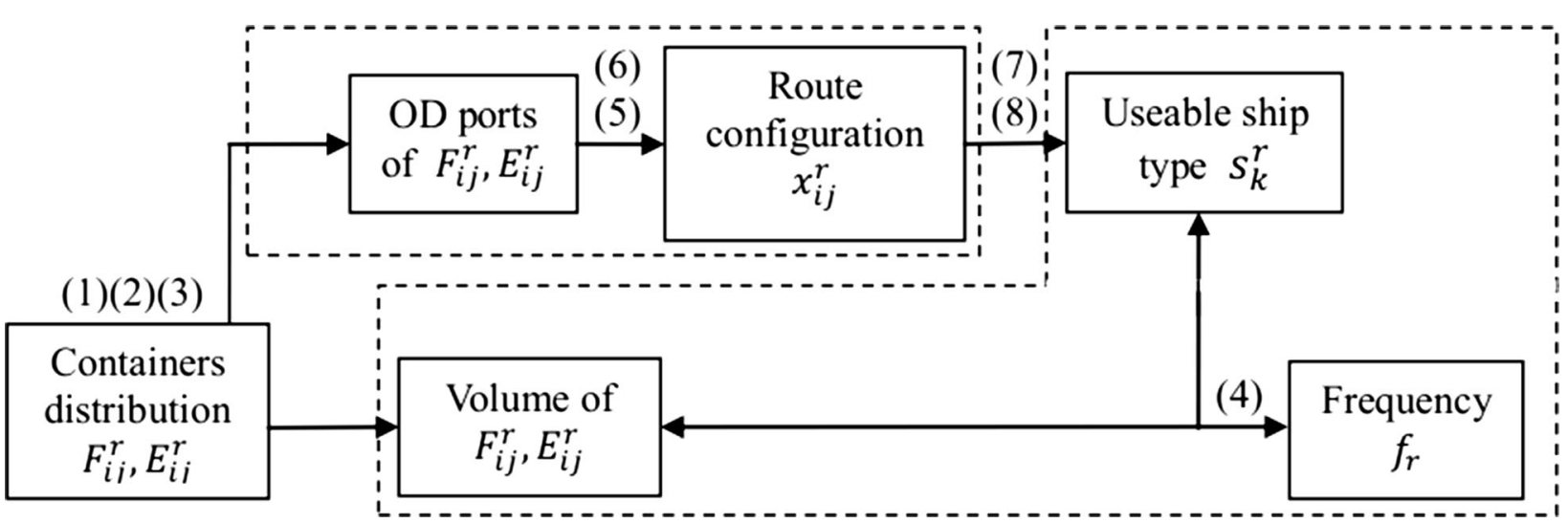

Fig. 2 Constraint relations between variables

Figure 3 shows how GA and IP are combined to solve the IWCT network design problem. The running steps are as follows:

- Step 1: population initialization. Set $N=0$ and generate an initial population with the following coding method

Coding method: The chromosome of the individual is coded as a matrix $\left[O_{i j 1}, O_{i j 2}, \ldots O_{i j r} \ldots, O_{i j R}\right]$, and it is made up of several sub-matrix $\left[O_{i j r}\right]$ when each one represent a route. The number $R$ can be determined by experience according to ports number and containers flow first. With the ports' number, the size of sub-matrix is $P^{*} P$, therefore the size of chromosome matrix is $P^{*}\left(P^{*} R\right)$. Each binary element $O_{i j}^{r}$ of sub-matrix $\left[O_{i j r}\right]$ represents whether OD containers from port $i$ to $j$ is distributed to route $r$ or not.

The same OD containers volume can be transported by more than one routes. We assumed that the laden containers routing from the original port to the destination

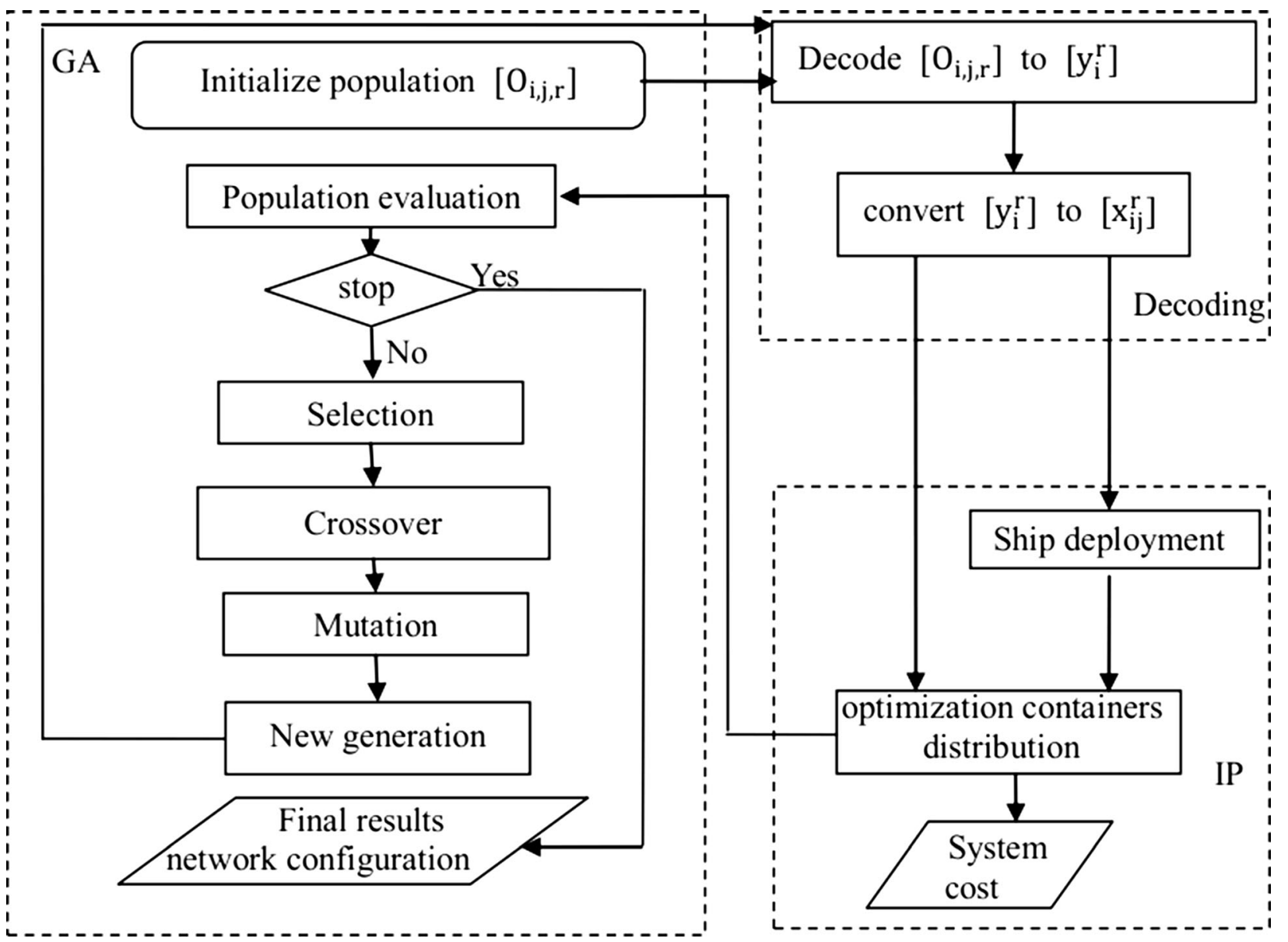

Fig. 3 IWCT network design solution algorithm representation 
port are limited with at most three service routes. This is valid because too many different services can lead to confusion of liner schedules. So among all the sub-matrix $\left[O_{i j r}\right], r \in\{1,2 \ldots, R\}$, only at most three same $i j$ locations' value are 1 , the rest are 0 . This coding method can thus describe any containers distribution strategy and combination of the shipping network.

- Step 2: Decoding of each individual

With the relation between $O_{i j}^{r}$ and $y_{i}^{r}$ described above, the calling ports of each route can be got first. Then according to round trip restrictions, each route's configuration $x_{i j}^{r}$ can be decided. For example, for route $r$, if $O_{24}^{r}=$ $O_{37}^{r}=O_{74}^{r}=1$, then $\mathrm{y}_{\mathrm{r}}^{2}=\mathrm{y}_{\mathrm{r}}^{4}=\mathrm{y}_{\mathrm{r}}^{3}=\mathrm{y}_{\mathrm{r}}^{7}=\mathrm{y}_{\mathrm{r}}^{4}=1$ and $\mathrm{x}_{23}^{\mathrm{r}}=\mathrm{x}_{34}^{\mathrm{r}}=$ $\mathrm{x}_{47}^{\mathrm{r}}=\mathrm{x}_{74}^{\mathrm{r}}=1$. Route $r$ should be closed, so $\mathrm{x}_{42}^{\mathrm{r}}=1$.

- Step 3: Calculation of the fitness value.

With the predetermination of routes configuration and preprocessing of available ship types, the mathematical model in part 4 has become a simple IP problem. The fitness value calculation is done by IP. After decoding, GA sends the information of routes configuration $x_{i j}^{r}$ to IP. IP will perform the optimization of the containers distribution and empty containers repositioning among all chosen routes and will define the related service frequency of each route to minimize the system cost $z$. Then the system cost is transferred to the fitness value of the individual in GA by: fit $=\frac{1}{\mathrm{z}} \rightarrow 10^{12}$.

- Step 4: check of number of iterations.

Checking whether the number of iterations in current generation is less than the maximum number of iterations, if no, go to Step 5; otherwise, terminate the calculation.

- Step 5: Implementation of selection, crossover, and mutation operations.

Let $n=n+1$ and get a new generation of individuals $P_{n}$. Then return to Step 2. In this step, the roulette wheel is used for the selection operation. And to make sure the offspring are feasible, crossover is operated between rows.

\section{Case study}

\subsection{Data preparation}

In this section, we present an application of the model established above to container transportation in Yangtze River based on real and predicted data. We select 7 ports with large container volumes on Yangtze River as the examples. From upstream to downstream, they are 1 Chongqing, 2 Yichang, 3 Chenglingji, 4 Wuhan, 5 Anqing, 6 Nanjing, 7 Shanghai. Table 1 gives the shipping distance between ports. About the influence of locks,
Table 1 The shipping distance between Yangtze River main line's main ports $\left(\mathrm{L}_{\mathrm{ij}} \mathrm{j}-\mathrm{km}\right)$

\begin{tabular}{llllllll}
\hline $\mathrm{O} \backslash \mathrm{D}$ & 1 & 2 & 3 & 4 & 5 & 6 & 7 \\
\hline 1 & & 560 & 1056 & 1283.5 & 1786 & 2092 & 2486 \\
2 & 560 & & 496 & 723.5 & 1226 & 1532 & 1926 \\
3 & 1056 & 496 & & 227 & 730 & 1036 & 1430 \\
4 & 1283 & 723 & 227 & & 502 & 808 & 1202 \\
5 & 1786 & 1226 & 730 & 502.5 & & 306 & 700 \\
6 & 2092 & 1532 & 1036 & 808.5 & 306 & & 394 \\
7 & 2486 & 1926 & 1430 & 1202.5 & 700 & 394 & \\
\hline
\end{tabular}

we just take Yangtse Gorges dam into consideration here which is located between 1 Chongqing and 2 Yichang. Suppose the average time needed to pass this lock is $5 \mathrm{~h}$. Table 2 gives the loaded container OD flows. Table 3 shows the alternative ship types with each one's related parameters. Due to the drought restriction, the allowed largest container capacity in every leg is different as shown in Table 4.

For other parameters, we set

(1) The planning horizon $\mathrm{H}: 1$ week

(2) Entry cost per call at port $i \cdot \mathrm{pc}_{\mathrm{i}}=5000 \mathrm{RMB}$

(3) Port entry time $e t_{i}=1 \mathrm{~h}$

(4) Loaded containers handling time $l t e_{i}+d t f_{j}=0.042 \mathrm{~h}$

(5) Empty containers handling time $l t e_{i}+d t e_{j}=0.040 \mathrm{~h}$

For parameters (2)-(5), they vary from port to port, but due to the lack of detailed data, we assume that they are the same for all the ports under consideration.

\subsection{Calculation and result}

For the calculation, the following genetic algorithm parameters were used:

- Population size: 50

- Probability of crossover: 0.90

- Probability of mutation:0.01

Table 2 Loaded container OD flows between ports $\left(\mathrm{F}_{\mathrm{ij}}-\mathrm{TEU} /\right.$ week $)$

\begin{tabular}{llllllll}
\hline $\mathrm{O} \backslash \mathrm{D}$ & 1 & 2 & 3 & 4 & 5 & 6 & 7 \\
\hline 1 & 0 & 178 & 256 & 716 & 87 & 345 & 3523 \\
2 & 220 & 0 & 120 & 248 & 361 & 183 & 226 \\
3 & 136 & 52 & 0 & 0 & 284 & 125 & 682 \\
4 & 450 & 156 & 0 & 0 & 172 & 314 & 3380 \\
5 & 197 & 342 & 322 & 438 & 0 & 80 & 341 \\
6 & 364 & 247 & 593 & 256 & 213 & 0 & 4486 \\
7 & 1879 & 194 & 503 & 1900 & 496 & 3547 & 0 \\
\hline
\end{tabular}


Table 3 The container capacity and relevant parameters of main ship types in Yangtze River

\begin{tabular}{lllll}
\hline $\begin{array}{l}\text { Ship } \\
\text { type }\end{array}$ & $\begin{array}{l}\text { Capability } u_{\mathrm{k}} \\
(\mathrm{TEU})\end{array}$ & $\begin{array}{l}\text { Speed } \mathrm{v}_{\mathrm{k}} \\
(\mathrm{km} / \mathrm{h})\end{array}$ & $\begin{array}{l}\text { Daily fuel cost } \\
\alpha_{\mathrm{k}}(\mathrm{RMB})\end{array}$ & $\begin{array}{l}\text { Daily charter cost } \\
\beta_{\mathrm{k}}(\mathrm{RMB})\end{array}$ \\
\hline 1 & 100 & 11 & 6000 & 2000 \\
2 & 150 & 11 & 12,000 & 3000 \\
3 & 200 & 12 & 19,000 & 5000 \\
4 & 300 & 13 & 30,000 & 7000 \\
\hline
\end{tabular}

- Maximum number of iterations:100

We compile the solving program with MATLAB R2009a combined with plug-in of CPLEX 12.1. Table 5 shows the result of the shipping network of the inland waterway system under consideration. The lowest cost of the system shipping network is $7.6598 \mathrm{e}+007 \mathrm{RMB}$.

A combination of short routes (direct route between two ports) and long routes are obtained in IWCT network design system. The direct link design is commonly used for moving large quantities of commodities between two ports. On the other hand, longer routes are used to bund cargo flows by calling as many ports as possible.

A combination of short routes (direct route between two ports) and long routes are obtained in the IWCT network design system. The direct links are commonly used for moving large quantities of containers between two ports, such as route 6-7-6,route 4-7-4, route 1-7-1, route 3-7-3 and route 1-41 , and there is a high frequency. On the other hand, for small containers flow, longer routes are used to bund cargo flows by calling as many ports as possible, as routes 5,8,9,11,13,14,17. This result is consistent with the actual situation. Point-topoint direct route is the most economic mode for large cargo flows between ports. However, when the containers flow is small, routes calling at multiple ports can achieve economies of scale through bundling.

Table 4 The allowed largest container capacity in every leg of Yangtze River $\left(\mathrm{G}_{\mathrm{ij}} \mathrm{j}\right.$ TEU)

\begin{tabular}{llllllll}
\hline O\D & 1 & 2 & 3 & 4 & 5 & 6 & 7 \\
\hline 1 & 0 & 150 & 150 & 150 & 150 & 150 & 150 \\
2 & 150 & 0 & 150 & 150 & 150 & 150 & 150 \\
3 & 150 & 150 & 0 & 200 & 200 & 200 & 200 \\
4 & 150 & 150 & 200 & 0 & 200 & 200 & 200 \\
5 & 150 & 150 & 200 & 200 & 0 & 300 & 300 \\
6 & 150 & 150 & 200 & 200 & 300 & 0 & 300 \\
7 & 150 & 150 & 200 & 200 & 300 & 300 & 0 \\
\hline
\end{tabular}

Table 5 The calculation result

\begin{tabular}{llll}
\hline Route & Ports to call & $\mathrm{f}_{\mathrm{r}}$ & Ship capability \\
\hline 1 & $6-7-6$ & 15 & 300 \\
2 & $4-7-4$ & 14 & 200 \\
3 & $1-7-1$ & 9 & 150 \\
4 & $3-7-3$ & 2 & 200 \\
5 & $2-4-6-7-6-2$ & 5 & 150 \\
6 & $1-4-1$ & 3 & 150 \\
7 & $1-6-1$ & 2 & 150 \\
8 & $1-7-4-2-1$ & 3 & 150 \\
9 & $1-2-4-5-4-1$ & 2 & 100 \\
10 & $3-6-3$ & 5 & 200 \\
11 & $1-2-3-2-1$ & 3 & 150 \\
12 & $4-7-4$ & 7 & 200 \\
13 & $3-4-5-6-4-3$ & 4 & 200 \\
14 & $4-6-7-6-5-4$ & 3 & 200 \\
15 & $5-6-7-5$ & 7 & 300 \\
16 & $2-3-2$ & 1 & 150 \\
17 & $1-3-4-6-5-3-1$ & 5 & 150 \\
18 & $2-4-5-2$ & 3 & 150 \\
\hline
\end{tabular}

\section{Conclusion and discussion}

In this paper, we address the problem of inland water systematic container shipping network design with empty containers repositioning. This problem is dealt by forming a mixed integer nonlinear model. Base on the computational experience, a set of routes and their corresponding ships as well as the optimizing cost are figured out. By doing this, the IWCT service level can be increased by satisfying the containers transportation demand as well as minimizing the total operation cost. Therefore, the competitiveness of the waterway may get stronger to attract more containers from land modes. Base on the result of study, the following conclusions are drawn:

(1) While there are plentiful literatures about ocean shipping and intermodal network analysis, the study of inland waterway container shipping is still rare. So there is great necessity of study for IWCT service network design.

(2) For the IWCT service network design, the specific features of IWCT need to be taken into consideration. Because of this, the proposed model is suitable for the service network design in IWCT network. And the experimental results verify the validity of the combined algorithm.

(3) In accord with real situation, a set of routes containing point-to-point direct routes and routes calling at multiple ports are figured out for different containers flow. 
The inland waterway container network design and operation is of great systematic guide significance for mode shift and sustainability development of transportation. Meanwhile, it can help to realize bundling of containers not only within an individual liner service but also by combining two or more liner services so as to guide cooperation between shipping companies.

This study does some exploration to the network design of inland water shipping system. We wish this can help to promote follow-up studies of inland container liner service network planning progress. However, the network design in inland waterway liner transportation cannot be well finished by one study, there are also some limitations. Because it is hard to get the real OD containers transportation demand and cost, we have not done the comparison between the real cost and the optimized cost so as to certify the advantage of the network design method. This can be an interesting direction for future research.

Considering the repositioning of empty containers, no leasing and storage option is considered in the IWCT network design system, because continuously leasing containers at a certain port and storing containers at another port will generate additional cost and cannot ensure the system sustainability. However, the quantitative studies about whether the empty containers repositioning strategy in our study is of advantage compared with the leasing and storage strategy or not has not been done here. Service network design in inland waterway liner transportation with empty container repositioning under the leasing and storage strategy can also be addressed in future.

Open Access This article is distributed under the terms of the Creative Commons Attribution License which permits any use, distribution, and reproduction in any medium, provided the original author(s) and the source are credited.

\section{References}

1. Wieberneit N (2008) Service network design for freight transportation: a review. OR Spectr 30(1):77-112

2. Sambracos E, Paravantis JA, Tarantilis CD, Kiranoudis CT (2004) Dispatching of small containers via coastal freight liners: the case of the Aegean Sea. Eur J Oper Res 152(2):365-381
3. Fagerholt K (2004) Designing optimal routes in a liner shipping problem. Marit Policy Manag 31(4):259-268

4. Karlaftis MG, Kepaptsoglou K, Sambracos E (2009) Containership routing with time deadlines and simultaneous deliveries and pickups. Transp Res E Logist Transp Rev 45(1):210-221

5. Christiansen M, Ronen D, Nygreen B, Fagerholt K (2007) Maritime transportation. Handb Oper Res Manag Sci 14:189-284

6. Hsua C-I, Hsieha Y-P (2007) Routing, ship size, and sailing frequency decision-making for a maritime hub-and-spoke container network. Math Comput Model 45(7-8):899-916

7. Gelareh S, Pisinger D (2011) Fleet deployment, network design and hub location of liner shipping companies. Transp Res E Logist Transp Rev 47(6):947-964

8. Wang S, Meng Q (2012) Liner ship fleet deployment with container transshipment operations. Transp Res E Logist Transp Rev 48(2): 470-484

9. Caris A, Macharis C, Janssens GK (2008) Planning problems in intermodal freight transport: accomplishments and prospects. Transp Plan Technol 31(3):277-302

10. Sharypova K, van Woensel T, Fransoo JC (2012) Coordination and analysis of barge container hinterland networks

11. Newman AM, Yano CA (2000) Centralized and decentralized train scheduling for intermodal operations. IIE Trans 32(8):743-754

12. Racunica I, Wynter L (2005) Optimal location of intermodal freight hubs. Transp Res B Methodol 39(5):453-477

13. Yoon MG, Current J (2006) The hub location and network design problem with fixed and variable arc costs: formulation and dualbased solution heuristic. J Oper Res Soc 59(1):80-89

14. Andersen J, Crainic TG, Christiansen M (2009) Service network design with asset management: Formulations and comparative analyses. Transp Res C Emerg Technol 17(2):197-207

15. Crainic TG (2000) Service network design in freight transportation. Eur J Oper Res 122(2):272-288

16. Van Der Horst MR, De Langen PW (2008) Coordination in hinterland transport chains: a major challenge for the seaport community. Marit Econ Logist 10(1):108-129

17. Caris A, Janssens G (2008) Macharis C. Service network design in intermodal barge transport

18. Caris A, Macharis C, Janssens GK (2011) Network analysis of container barge transport in the port of Antwerp by means of simulation. J Transp Geogr 19(1):125-133

19. Veenstra AW, Zhang M, Ludema M (2008) The growth potential of container shipping on the Yangtze River. Marit Policy Manag 35(6): 535-549

20. Marasš V (2008) Determining optimal transport routes of inland waterway container ships. Transp Res Rec J Transp Res Board 2062(1): $50-58$

21. Yang Z, Shi H, Chen K, Bao H (2013) Optimization of container liner network on the Yangtze River. Marit Policy Manag, (ahead-of-print), $1-18$

22. Shintani K, Imai A, Nishimura E et al (2007) The container shipping network design problem with empty container repositioning. Transp Res E Logist Transp Rev 43(1):39-59 